\title{
Trabalho docente no ensino médio no Brasil
}

\author{
Gilvan Luiz Machado Costa* \\ Dalila Andrade Oliveira*
}

\section{Resumo}

Este artigo tem como objetivo discutir quem são os sujeitos docentes do ensino médio e suas condiçôes de trabalho, a partir de dados estatísticos disponíveis em fontes oficiais e na literatura. Segundo tais dados, os professores do ensino médio no Brasil, em relação aos da educação infantil e ensino fundamental, têm mais aulas, turmas, alunos, turnos e empregos. O texto parte da caracterizaçáo do contexto de reformas educacionais que o país viveu nas duas últimas décadas, resultando em expansão quantitativa da matrícula em educação básica, o que tem trazido consequências importantes para os docentes do ensino médio. Os docentes da última etapa da educação básica não contam com condiçóes de trabalho e remuneração à altura das inúmeras demandas que chegam às escolas. As condições de trabalho, carreira e remuneraçáo desses docentes podem ter, como resultado, uma baixa atratividade da carreira do magistério no Brasil.

Palavras-chave: Condiçóes do trabalho docente. Ensino médio. Docente.

* Doutor em Educaçáo pela Universidade Estadual de Campinas. Professor do Mestrado em Educação da Universidade do Sul de Santa Catarina.

** Doutora em Educaçáo pela Universidade de São Paulo. Professora Titular da Faculdade de Educação e do Programa de Pós-Graduação em Educação da Universidade Federal de Minas Gerais. 


\section{Introdução}

A escola aparece hoje como uma instituiçáo frequentada pela quase totalidade da população brasileira de 6 a 14 anos. A ampliação do acesso à educação básica em todas as suas etapas tem sido um fato significativo nos últimos anos. Em 2010, a matrícula na educaçáo básica no Brasil foi de 51.549.889 alunos distribuídos entre a educação infantil, ensino fundamental e o ensino médio (BRASIL, 2010).

As políticas educacionais no Brasil das duas últimas décadas tiveram como orientação a busca da equidade social, perseguindo, como prioridade, a universalização do ensino fundamental; mais recentemente, procuraram ampliar o acesso ao ensino médio e à educação infantil. $\mathrm{O}$ Fundo de Manutençáo e Desenvolvimento da Educaçáo Básica e de Valorização dos Profissionais da Educaçáo (FUNDEB), que substituiu o Fundo de Manutenção e Desenvolvimento do Ensino Fundamental e de Valorização do Magistério (FUNDEF), é uma demonstração de tais intençôes, ao ampliar a abrangência do financiamento a etapas e modalidades da educação anteriormente excluídas do Fundef. A Emenda Constitucional no 59, de 2009, cuja redaçáo alterou os incisos I e VII, do artigo 208, prevê a obrigatoriedade do ensino de quatro a dezessete anos, o que representa importante medida legal nessa direção.

Ao ampliar o acesso à educação básica e abrir a escola pública à população em situação vulnerável, as reformas educacionais ocorridas no Brasil, nas últimas décadas, buscaram a promoção da justiça social pela diminuição das desigualdades sociais. Ao buscar, com a ampliação do acesso e da permanência na escola, a formação da força de trabalho articulada à distribuição de renda e assistência social, as políticas educacionais foram, ao mesmo tempo, políticas de desenvolvimento e políticas sociais (ASSUNÇÃO; OLIVEIRA, 2009).

A lógica adotada para as mudanças tem sua gênese na reforma do Estado que, a partir de 1990, assume uma forma de gestáo baseada nos princípios da descentralização administrativa e financeira. A escola passa a assumir maiores responsabilidades na conduçáo do processo educacional, assim como na captação de recursos para atingir as metas determinadas pelos órgãos centrais. Observa-se um processo contraditório; ao mesmo tempo em que a escola adquire maior autonomia, vê-se constrangida a responder aos 
processos de avaliação externa e a políticas que são definidas centralmente. Com a Emenda Constitucional no 14, de 1996, o ensino fundamental e a educação infantil passaram a ser responsabilidade prioritária dos municípios, e o ensino médio, dos estados. Com a criação do Fundef, em 1996, o movimento de ampliação das matrículas na educação básica intensifica-se e ganha novos contornos. As redes estaduais e municipais, na tentativa de responder à divisão de competências definidas a partir da referida Emenda Constitucional, desenvolvem diferentes açôes. Novas escolas são construídas, escolas estaduais de ensino fundamental são municipalizadas, aumenta-se o número de alunos por sala, intensifica-se a utilização do turno noturno e, em algumas situações, cria-se um turno intermediário. Com a ampliação da cobertura de matrícula que se verificou nas duas décadas passadas, as escolas públicas brasileiras chegaram à atualidade com novas demandas e desafios. Contudo, a realidade dessas escolas varia de acordo com sua localização geográfica, com a capacidade de financiamento de seus estados e municípios, bem como em função de outros fatores que são distribuídos desigualmente na realidade brasileira. Nesse contexto desigual, as políticas educacionais mesclaram a noção de justiça social com os princípios de eficácia, "revelando em certa medida um movimento contraditório: a democratização do acesso à escola dá-se ao custo da massificação do ensino" (ASSUNÇÃO; OLIVEIRA, 2009, p. 351).

As ações foram exitosas ao proporcionarem a universalização do ensino fundamental e ampliarem, consideravelmente, o acesso às demais etapas da educação básica. Entretanto, a equidade social perseguida, com escolas abrindo suas portas para todos, no sentido de acolher a diversidade, não ocorreu em condiçôes adequadas no que se refere aos recursos econômicos e condiçóes de trabalho e de ensino. A ampliação do número de escolas para atender a um contingente maior de alunos exigiu, como consequência, o aumento do número de docentes. Contudo, com as condições desiguais de financiamento à educação que acontece no Brasil, tal ampliação tem efeitos diretos sobre a remuneração, as condições de trabalho e as funções/tarefas dos professores. A categoria docente, constituída de mulheres e homens que, para sobreviver, são obrigados a vender sua força de trabalho, e pertencente à "classe-que-vive-do-trabalho" (ANTUNES; ALVES, 2004), chegou ao século XXI mais numerosa, fragmentada, heterogênea e diversificada. 
A reforma educacional implantada no Brasil nas duas últimas décadas pode estar na contramão de uma educação de qualidade social. Tem-se, como hipótese, que as novas regulaçóes educativas atribuem mais responsabilidades aos docentes, que não dispóem, nas escolas públicas, de condiçôes apropriadas para realizar o seu trabalho. A nova regulação da política educacional, centrada na eficácia e na responsabilidade da escola, trouxe sérias consequências para os professores, provocando uma reestruturação de seu trabalho.

Após vinte e dois anos de aprovação da Constituição Federal e aproximadamente quinze da promulgação da LDBEN 9.394/96, vale questionar se as reformas que incidiram sobre as escolas de educação básica, os trabalhadores da educação e os estudantes resultaram em uma "escola pública de qualidade para todos, como direito social” (DOURADO; OLIVEIRA, 2008, p. 15).

Considerando a expansão sofrida pelo ensino médio nas duas últimas décadas e a perspectiva de maior ampliação com a obrigatoriedade recentemente inscrita em lei, ganha relevância a discussão sobre os trabalhadores docentes da última etapa da educação básica e as condições em que esses docentes realizam o seu trabalho.

$\mathrm{O}$ presente artigo discute algumas questóes relacionadas às novas regulaçóes das políticas educacionais e suas consequências sobre o trabalho docente na educação básica, sobretudo em sua última etapa. Para tanto, sem pretender esgotar o tema, a primeira seção deste artigo apresenta uma breve discussão sobre o trabalho docente no Brasil. Teve por base uma revisão de literatura, fazendo um levantamento de artigos publicados em periódicos da área de educação, sobretudo os disponíveis no portal Scielo, que tenham publicado estudos e dossiês sobre o trabalho docente.

$\mathrm{Na}$ segunda seção, faz-se um cotejo da discussão teórica com dados estatísticos sobre os professores do ensino médio, disponíveis em fontes oficiais, tais como: Ministério do Trabalho e Emprego (MTE), Pesquisa Nacional de Amostra por Domicílios (PNAD), Ministério da Educação (MEC), e Instituto Nacional de Estudos de Pesquisas Educacionais Anísio Teixeira (INEP).

Discute-se, por fim, em que medida as orientaçóes perseguidas pelas reformas educacionais das últimas décadas têm conseguido articular 
a ampliação da cobertura educacional e a situação dos docentes. O que se observa é um contexto bastante marcado por condiçóes precárias de trabalho e remuneração do professor do ensino médio, que podem trazer efeitos diretos sobre a atratividade da carreira docente e a formação dos futuros professores.

\section{O trabalho docente no debate educacional}

O campo educacional apresenta, nessa primeira década do novo século, um paradoxo preocupante: mesmo com a centralidade atribuída à educação escolar, "faltam" professores habilitados para lecionar nas escolas públicas brasileiras, sobretudo no ensino médio (BRASIL, 2007a). Segundo Dourado e Oliveira (2008), chama atenção a forma como esse problema foi enfrentado pelos governos dos últimos 20 anos: a aposta na ampliação do acesso a cursos de formação inicial. A opçáo pela ampliação das vagas nos cursos de licenciatura sugere que as discussóes e açóes no campo educacional não incidiram uniformemente sobre o estatuto econômico, social e científico dos professores.

A organização e expansão da formação de professores foram exaustivamente debatidas nos meios acadêmicos e passaram por algumas mudanças; todavia, o mesmo parece não se verificar com o trabalho docente. Em um contexto marcado por novas regulaçóes educacionais que atingiram duramente as condiçóes materiais e simbólicas do trabalho docente, "as investigaçóes acadêmicas dedicadas a investigar o tema foram menos numerosas" (LEHER; LOPES, 2008, p. 1).

Destaca-se, a partir dos primeiros anos do século XXI, a retomada do debate sobre as condiçóes objetivas de trabalho do professor. Ganham proeminência, no Brasil, pesquisas cujos resultados demonstram os desafios e dificuldades dos professores para responderem às demandas trazidas às escolas públicas na atualidade, sem que as condiçóes objetivas e subjetivas sejam substancialmente modificadas (OLIVEIRA, 2006). Adquirem ênfase "investigações que procuram contemplar a difícil equação entre a macrorrealidade dos sistemas educacionais e o cotidiano escolar" (OLIVEIRA, 2004, p. 1.128). Corroborando esse entendimento, Mancebo (2007) afirma que o trabalho docente, para ser investigado em sua totalidade, exige certa cautela metodológica, de tal modo que se possa permitir um 
fecundo diálogo entre a teoria e a confrontação empírica dos contextos em que ele se realiza.

Boa parte dos estudos sobre o trabalho docente destaca a centralidade atribuída pelas reformas educacionais à administração escolar, elegendo a escola como núcleo do planejamento e da gestáo; o financiamento per capita, presente no ensino fundamental e, mais recentemente, incluindo a educaçáo infantil e o ensino médio; a regularidade e ampliação dos exames nacionais de avaliação; a avaliação institucional e de desempenho; outros mecanismos de gestão escolar que insistem na participação da comunidade, bem como a proliferação de conselhos com funções consultivas (OLIVEIRA, 2008; MANCEBO, 2007; HYPÓLITO, 2008).

Esses estudos apontam a educação para a equidade social, proposta pela Conferência Mundial sobre Educação para Todos (DECLARAÇÃO, 1990), realizada em Jomtien, Tailândia, em março de 1990, como o marco das reformas educacionais dos países mais pobres e populosos do mundo, o que inclui o Brasil. A partir de Jomtien, buscou-se ampliar o atendimento escolar às populaçóes menos favorecidas economicamente. A ampliação das ofertas educacionais foi buscada por meio de estratégias de gestão e financiamento, que vão desde a focalização das políticas públicas educacionais ao apelo ao voluntarismo e ao comunitarismo (OLIVEIRA, 2006).

\section{A matrícula no ensino médio no Brasil}

A expansão da educação básica no Brasil tem ocorrido, ainda que tardiamente, quando comparada a vários países vizinhos. As redes municipais de ensino apresentaram 23.722.411 matrículas em 2010, superando a rede estadual, que apresentou 20.031.988, e a rede particular, com um total de 7.560.382. A rede federal de ensino apresentou 235.108 matrículas em suas escolas técnicas. Os estados e municípios, portanto, concentram a maior parte das matrículas. Em 2010, foram 43.754 .399 alunos matriculados nas escolas públicas municipais e estaduais brasileiras de educação básica (BRASIL, 2010).

O ensino médio conta com 8.357.675 matrículas nas diferentes dependências administrativas. Comparando com os dados do Instituto Nacional de Estudos de Pesquisas Educacionais Anísio Teixeira (INEP), evidencia-se um acréscimo de 20.515 em relação aos 8.337.160 de alunos 
matriculados na última etapa da educação básica em 2009. Trata-se de um acréscimo tímido, porém aponta para a possiblidade de trazer para as escolas de ensino médio os jovens que estão fora delas (BRASIL, 2010).

A rede estadual de ensino, que concentra a maioria dos alunos matriculados na última etapa da educação básica, teve uma expressiva ampliação nas duas últimas décadas. Das 2.472.964 de matrículas na referida dependência administrativa em 1991, passou-se para 7.177.019, em 2010. O mesmo crescimento não se verifica com a rede privada que, em 1991, contemplava 1.019.374 e recuou para 987.838, em 2010 (BRASIL, 2010).

A concepção de ensino médio que prevalece é de educação geral, como mostra a Tabela 1. Em 2009, foram 7.966.794 matrículas nesse modelo, das quais 6.914.978 em escolas públicas estaduais (BRASIL, 2009a). A importância de articular formação geral e formação profissional estabelecida pelo Decreto no 5.154/2004, que revogou o Decreto no ${ }^{-}$2.208/97, não se concretizou. $\mathrm{O}$ ensino médio integrado à educação profissional registrou, em 2009, apenas 175.831 matrículas (BRASIL, 2009a). O ideário presente no Decreto no 2.208/97, mesmo revogado, ofusca o Decreto no 5.154/2004, com o predomínio da matrícula na modalidade de educação geral, como já apontado (KUENZER, 2010).

Tabela 1 - Número de matrículas no ensino médio, educação geral, normal/ magistério e integrado, por dependência administrativa - 2009

\begin{tabular}{l|c|c|c|c|c}
\hline \multirow{2}{*}{ Total } & \multicolumn{4}{c}{ Dependência Administrativa } \\
\cline { 3 - 6 } \multicolumn{2}{c|}{} & Federal & Estadual & Municipal & Privada \\
\hline Brasil & 8.337 .160 & 90.353 & 7.163 .020 & 110.780 & 973.007 \\
\hline Educação Geral & 7.966 .794 & 29.040 & 6.914 .978 & 79.922 & 942.854 \\
\hline Normal/Magistério & 194.535 & - & 163.482 & 22.537 & 8.516 \\
\hline Integrado & 175.831 & 61.313 & 84.560 & 8.321 & 21.637 \\
\hline
\end{tabular}

Fonte: Elaboração dos autores, a partir de dados do MEC/INEP/Diretoria de Estatísticas Educacionais (DEED) (2009a)

Esses números nos permitem considerar que a maioria dos professores da última etapa da educação básica está concentrada nas redes estaduais de ensino. São profissionais dos quais se cobram os mesmos requisitos de formação, mas que são contratados e se encontram submetidos a distintas 
possibilidades salariais, carreira e condiçóes de trabalho. De acordo com as competências constitucionais que definiram o pacto federativo no Brasil a partir de 1988, os estados e municípios brasileiros respondem diferentemente pelas obrigaçóes com a educação e têm autonomia para estabelecer suas próprias carreiras e formas de remuneração dos docentes. Sendo assim, é necessário considerar que a discussão sobre as condições de trabalho e emprego dos docentes do ensino médio, ainda que apresentem baixa atratividade no geral, comportam diferentes situações nas redes públicas em que estão inseridos.

A ampliação de vagas na educação básica e as demais mudanças trazidas pelas reformas dos anos 1990, conforme já mencionadas, sobrecarregaram o docente, atribuindo-lhe mais responsabilidade, para além das relacionadas à sala de aula (OLIVEIRA, 2006). Ampliam-se as funçôes docentes, incluindo cuidar das demandas oriundas dos contextos de pobreza que marcam os alunos das escolas públicas. Soma-se o apelo à participação do coletivo dos professores na gestão democrática da escola e o aumento quantitativo dos dias letivos, que passaram de 180 para 200 dias. Passa a fazer parte do repertório do professor, segundo Oliveira (2004), desempenhar funçóes de agente público, assistente social, enfermeiro, psicólogo, entre outras.

As novas regulaçóes das políticas educacionais incidem sobre o trabalho do professor, reorganizando-o. As atividades em sala de aula e fora dela compóem o trabalho docente na contemporaneidade. Segundo Oliveira (2006), o conceito de trabalho docente se amplia e pode abarcar tanto os sujeitos nas suas complexas dimensões, experiências e identidades, quanto às condições em que as atividades são realizadas no ambiente escolar. Compreende, portanto, tal conceito, as atividades, responsabilidades e relaçóes que se realizam na escola para além da regência de classe, sujeitas, no conjunto, a mecanismos implantados pela gestão na busca por redução dos custos e aumento da eficácia.

\section{O professor do ensino médio e o seu trabalho}

Com mais de 51 milhóes de matrículas nas etapas constitutivas da educação básica, em 2010, observa-se uma grande demanda por professores no Brasil. No primeiro ano da década passada, encontravamse 259.380 funçóes docentes no ensino médio. Vale ressaltar que o 
número de funçóes docente é maior que o número de professores que, em 2009, alcançou a marca de 461.542. Com base na resolução da Câmara de Educação Básica de 1998, que institui as Diretrizes Curriculares Nacionais para o Ensino Médio - Educação Geral -, trata-se em sua maioria de professores de 12 disciplinas: Física, Química, Matemática, Biologia, Língua Portuguesa, Língua Estrangeira, Artes, Educação Física, História, Geografia, Filosofia e Sociologia. São 78.628 professores de Língua Portuguesa, o maior número, seguido por 67.447 professores de Matemática (BRASIL, 2009b). É inegável o tamanho da categoria de professores da última etapa da educação básica, que tende a aumentar, considerando-se a ampliação recente da obrigatoriedade da escolaridade dos 4 aos 17 anos (OLIVEIRA, 2010).

Ao considerarem-se os 461.542 professores da última etapa da educação básica, percebe-se que 351.642 deles são vinculados à dependência administrativa estadual; logo, são 27 possibilidades salariais, de carreira e condições de trabalho, no caso específico do ensino médio, se consideramos que o Brasil conta com 26 estados e o Distrito Federal. Desse total, apenas 165.784 são do gênero masculino; portanto, a maioria é feminina, ainda que a presença do gênero masculino no ensino médio seja superior à das demais etapas da educação básica. A idade elevada destaca-se entre os professores do ensino médio, pois 213.678 têm mais de 40 anos (BRASIL, 2009b). Trata-se de um grupo de trabalhadores com características muito próprias, como mostra a Tabela 2. Pode-se inferir que os professores do ensino médio apresentam determinadas singularidades próprias das especificidades do trabalho nessa etapa da educação básica.

Tabela 2 - Professores da pré-escola e ensino médio da educação básica, segundo a dependência administrativa, gênero e idade predominante

\begin{tabular}{c|c|c|c|c|cc}
\hline \multirow{2}{*}{$\begin{array}{c}\text { Etapa da } \\
\text { educaçáo } \\
\text { básica }\end{array}$} & \multicolumn{2}{|c|}{$\begin{array}{c}\text { Dependência } \\
\text { administrativa }\end{array}$} & \multicolumn{2}{c|}{ Gênero } & \multicolumn{2}{c}{ Faixa etária } \\
\cline { 2 - 8 } & Estadual & Municipal & Masculino & Feminino & Até 24 & Mais de 40 \\
\hline $\begin{array}{l}\text { Ensino } \\
\text { médio }\end{array}$ & 351.642 & 6.469 & 165.784 & 295.758 & 17.073 & 213.678 \\
\hline Pré-Escola & 3.474 & 176.554 & 10.054 & 248.171 & 37.630 & 81.759 \\
\hline
\end{tabular}

Fonte: MEC/INEP/DEED (2009b) 
A expansão da matrícula do ensino médio, na modalidade educação geral, nas escolas públicas estaduais, e o grande número de professores são uma realidade no Brasil. Mas em que condiçóes se realiza o trabalho docente nas escolas da última etapa da educação básica? Aspectos relacionados, por exemplo, à infraestrutura das escolas de ensino médio são fundamentais para o trabalho do professor.

Dados do Inep, de 2010, revelam que elementos estruturais de suporte às escolas de ensino médio são inadequados, com ausência de quadra de esportes, biblioteca, laboratório de informática, acesso à internet, laboratórios de ciências e dependências e vias adequadas a todos os alunos, como mostra a Tabela 3 (BRASIL, 2010). A ausência de laboratórios de ciências, por exemplo, é constatada em $51,7 \%$ das escolas da última etapa da educação básica. A inadequação da infraestrutura tem reflexos sobre o trabalho docente, que requer um ambiente escolar agradável, capaz de oferecer aos alunos instrumentos que favoreçam a aprendizagem, e seja estímulo para sua permanência na escola (BRASIL, 2010).

Tabela 3 - Número de escolas, matrículas e percentual de matrículas e escolas atendidas segundo a infraestrutura das escolas - ensino médio regular - Brasil, 2010

\begin{tabular}{l|c|c|c|c}
\hline \multirow{2}{*}{\multicolumn{1}{c|}{ Infraestrutura }} & \multicolumn{4}{|c}{ Ensino Médio Regular } \\
\cline { 2 - 5 } & Escolas & Matrículas & $\begin{array}{c}\% \\
\text { Escolas } \\
\text { Atendidas }\end{array}$ & $\begin{array}{c}\% \\
\text { Matrículas } \\
\text { Atendidas }\end{array}$ \\
\hline Quadra de Esporte & 19.618 & 6.677 .681 & 75,7 & 79,9 \\
\hline Biblioteca & 19.175 & 6.121 .164 & 74,0 & 73,2 \\
\hline $\begin{array}{l}\text { Laboratório de } \\
\text { Ciências }\end{array}$ & 12.785 & 4.726 .535 & 49,3 & 56,6 \\
\hline $\begin{array}{l}\text { Laboratório de } \\
\text { Informática }\end{array}$ & 23.153 & 7.810 .299 & 89,3 & 93,5 \\
\hline
\end{tabular}

Fonte: MEC/INEP/DEED (2010)

Os trabalhadores da educação constituem uma categoria numerosa. Pagar bons salários para 1.627.707 professores da educação básica que atuam nas escolas públicas (BRASIL, 2009b), como é o caso brasileiro, seria natural para um Estado plenamente comprometido com a ampla formação de 
suas crianças, jovens e adolescentes. Entretanto, as pesquisas têm apontado em outra direção. Ao considerar as últimas cinco décadas da história dos trabalhadores da educação, percebe-se que foram cinquenta anos de forte arrocho salarial (GARCIA; ANADON, 2009).

Os baixos salários dos professores, a partir da instauração do regime militar no Brasil, também são destacados por Ferreira Junior e Bittar (2006). Para os autores, essa situação se mantém, considerando que os governos democráticos dos últimos vinte anos não reverteram o quadro de perdas salariais dos docentes. As políticas educacionais implantadas durante a ditadura e as políticas neoliberais adotadas, a partir da década de 1990, distanciaram na linha do horizonte "a possibilidade da libertação espiritual e econômica do professor, mediante uma formação e remuneração que lhe confiram dignidade e prestígio" (FERREIRA JUNIOR; BITTAR, 2006, p. 1.174).

Com base em dados disponibilizados em 2010 pelo Sindicato dos Professores e Servidores no Estado do Ceará, verificam-se condiçôes salariais desiguais nos estados da Federação e no Distrito Federal. A diferença entre o maior salário-base e o menor é de, aproximadamente, $\mathrm{R} \$ 1.600,00$. O estado do Acre se destaca com um salário-base de $\mathrm{R} \$ 2.234,38$, recebidos por professores com licenciatura plena, para uma jornada de 40 horas-aula semanais. Por outro lado, os professores que lecionam nas escolas estaduais de Pernambuco recebiam R\$ 635,00 em 2010. Destaca-se que a média salarial dos professores licenciados que trabalham no ensino médio nas escolas públicas estaduais é de $\mathrm{R} \$ 1.300,00$, e a mediana fica em torno de $\mathrm{R} \$ 1.200,00$. Tal cifra é próxima de $\mathrm{R} \$ 1.187,08$, valor do piso nacional dos professores de ensino básico das escolas públicas brasileiras, em 2011. A Tabela 4 explicita a média e a mediana relacionadas ao salário dos professores das três etapas da educação básica.

Tabela 4 - Remuneração (em R \$) dos professores da educação básica/2006

\begin{tabular}{c|c|c|c|c|c}
\hline \multirow{2}{*}{ País } & \multirow{3}{*}{ Parâmetro } & \multicolumn{3}{|c|}{ Nível de Ensino } & \multirow{2}{*}{ Total } \\
\cline { 3 - 5 } Brasil & $\begin{array}{c}\text { Educaçáo } \\
\text { Infantil }\end{array}$ & $\begin{array}{c}\text { Ensino } \\
\text { Fundamental }\end{array}$ & $\begin{array}{c}\text { Ensino } \\
\text { Médio }\end{array}$ & \\
\cline { 2 - 5 } & Média & 661 & 873 & 1.390 & 927 \\
\cline { 2 - 5 } & Mediana & 500 & 700 & 1.200 & 720 \\
\hline
\end{tabular}

Fonte: Pesquisa Nacional por Amostra de Domicílios (PNAD)/Instituto Brasileiro de Geografia e Estatística (IBGE) (2006) 
Para Sampaio e Marin (2004), a precarização do trabalho docente se torna mais aguda com os salários recebidos pelos professores, pois a pauperização profissional significa empobrecimento da vida pessoal nas suas relaçóes entre vida e trabalho, sobretudo no que tange ao acesso a bens culturais.

A carreira na educação básica realizada pelo professor no Brasil mostrase pouco atraente em termos salariais e de progressão. A Tabela 5 mostra que o salário dos professores é inferior quando comparado aos salários pagos em outros países, assim como a ampliação da remuneração por meio do tempo de serviço e participação em cursos de formação continuada também são pequenas em termos percentuais em relação a outras naçóes.

Tabela 5 - Remuneração (em US\$) no início e fim da carreira dos professores que lecionam em escolas públicas/2002

\begin{tabular}{c|c|c|c|c|c|c}
\hline \multirow{2}{*}{ País } & \multicolumn{2}{|c|}{$\begin{array}{c}\text { Ensino Fundamental } \\
\text { 6o ao } 9 \text { a ano }\end{array}$} & \multirow{2}{*}{ Variação } & \multicolumn{2}{|c|}{ Ensino Médio } & Variação \\
\cline { 2 - 7 } & Início & Fim & $\%$ & Início & Fim & $\%$ \\
\hline \multirow{2}{*}{$\begin{array}{c}\text { Brasil } \\
\text { Argentina }\end{array}$} & 14.820 & 18.723 & 26,3 & 15.500 & 19.776 & 27,6 \\
\cline { 2 - 7 } & 14.623 & 25.742 & 76 & 14.623 & 25.742 & 76 \\
\hline Coréia do Sul & 26.148 & 69.666 & 166,4 & 26.148 & 69.666 & 166,4 \\
\hline Alemanha & 34.891 & 46.180 & 32,3 & 37.394 & 52.004 & 39 \\
\hline
\end{tabular}

Fonte: Education at a glance (OCDE) (2002)

A ampliação das matrículas nas últimas duas décadas representou a expansão da rede pública de ensino. Como uma das consequências, verificase um número expressivo de professores contratados temporariamente, em condiçóes precárias no setor público, representando significativa economia para os cofres dos estados e municípios (OLIVEIRA, 2008). A Tabela 6 demonstra o percentual de professores admitidos em caráter temporário em 2007.

Os professores com contratos temporários não possuem garantias trabalhistas e previdenciárias, recebem menores salários, não contam com a estabilidade e estáo submetidos a relaçóes informais de trabalho, com menos direitos e garantias sociais. A adoção de formas variadas de prestação 
de serviços em caráter temporário torna precário o trabalho docente (OLIVEIRA, 2008).

Tabela 6 - Professores efetivos e temporários no setor público

\begin{tabular}{c|c|c}
\hline \multicolumn{3}{|c}{ Situação do Emprego } \\
\hline Efetivo & Efetivo & Temporário \\
\hline País & $\%$ & $\%$ \\
\hline Brasil & 74,2 & 25,8 \\
\hline Coréia do Sul & 95,6 & 4,4 \\
\hline
\end{tabular}

Fonte: OCDE, TALIS (2007-2008)

A baixa remuneração e a possibilidade de contratos temporários contribuíram para que o professor da escola pública ampliasse sua jornada de trabalho. A Tabela 7 mostra que os professores da educação básica, particularmente os que lecionam no ensino médio, possuem uma carga horária extensa, com ampla utilização do turno noturno, haja vista que nele estão matriculados 2.875 .834 alunos, ou seja, 34,4\% das matrículas da última etapa da educação básica (BRASIL, 2010). São muitas aulas e muitas turmas, considerando o pequeno número de aulas de cada uma das 12 disciplinas distribuídas nas 25 aulas semanais que compóem o currículo da educação geral. Menos aulas por disciplina, mais turmas e turnos.

Tabela 7 - Número de horas trabalhadas no ensino médio/2006

\begin{tabular}{c|c|c|c|c}
\hline \multirow{2}{*}{$\begin{array}{c}\text { Nível de Ensino no } \\
\text { Trabalho }\end{array}$} & \multicolumn{4}{|c}{ Administração } \\
\cline { 2 - 5 } & \multicolumn{2}{|c}{ Privada } & \multicolumn{2}{c}{ Pública } \\
\cline { 2 - 5 } & Média & Mediana & Média & Mediana \\
\hline $\begin{array}{c}\text { Ensino Fundamental } \\
\text { Anos Iniciais }\end{array}$ & 28 & 24 & 31 & 30 \\
\hline Ensino Médio & 28 & 26 & 33 & 40 \\
\hline
\end{tabular}

Fonte: PNAD/IBGE (2006)

Essa situação se torna ainda mais preocupante ao se constatar que 95.074 desses docentes possuem outras atividades além da docência, como mostra a Tabela 8 . Ser professor parece não ser a atividade principal de $25,1 \%$ dos que lecionam no ensino médio. 
Tabela 8 - Número de empregos dos professores do ensino médio no Brasil/2006

\begin{tabular}{c|c|c|c}
\hline \multirow{2}{*}{ Nível de Ensino } & \multicolumn{3}{|c}{ Número de Empregos } \\
\cline { 2 - 4 } & 1 & 2 & 3 \\
\hline Educação Infantil & 271.971 & 33.873 & 1.782 \\
\hline Ensino Médio & 284.013 & 81.360 & 13.714 \\
\hline
\end{tabular}

Fonte: PNAD/IBGE (2006)

O Estado, responsável por ampla maioria das matrículas das escolas públicas, é também avaliador, a partir da lógica estruturada e desenvolvida com base na cultura do desempenho e da descentralização. Em contexto de grande flexibilização do trabalho e de múltiplas funções atribuídas ao professor, desenha-se uma jornada de trabalho intensificada em que os tempos são cada vez mais preenchidos ao longo da jornada. Nesses casos, observa-se a intensificação do trabalho docente, entendida como a ampliação das tarefas, sem a ampliação do tempo (OLIVEIRA, 2006). A carga de trabalho torna-se mais pesada com a ampliação do número de alunos por turma, o que resulta em aumento do número de alunos por professor (SAMPAIO; MARIN, 2004). A Tabela 9 mostra que o número de alunos por turma no ensino médio na dependência administrativa estadual chega a, aproximadamente, 34 quando se consideram as 7.163 .020 matrículas distribuídas nas 212.134 turmas (BRASIL, 2010).

Tabela 9 - Número de matrículas no ensino médio, normal/magistério e integrado por número de turmas e dependência administrativa - Brasil, 2010

\begin{tabular}{l|c|c|c|c|c}
\hline \multirow{2}{*}{ Brasil } & \multirow{2}{*}{ Total } & \multicolumn{4}{|c}{ Dependência Administrativa } \\
\cline { 3 - 6 } & & Federal & Estadual & Municipal & Privada \\
\hline Matrículas & 8.337 .160 & 90.353 & 7.163 .020 & 110.780 & 973.007 \\
\hline Número de Turmas & 251.496 & 2.942 & 212.134 & 3.611 & 32.809 \\
\hline $\begin{array}{l}\text { Matrículas/Número } \\
\text { de Turmas }\end{array}$ & 33,15 & 30,71 & 33,76 & 30,67 & 29,65 \\
\hline
\end{tabular}

Fonte: MEC/INEP/DEED (2010)

Ao fazer uma análise da matrícula na última etapa da educação básica, considerando apenas os dados de 2009 fornecidos pelo INEP, percebe-se que 8.060.799 localizam-se em escolas consideradas urbanas, ou seja, 96,68\%. 
Dos alunos, apenas 62,44\% têm entre 15 e 17 anos. Esse percentual pode ser menor na dependência administrativa estadual, haja vista sua maior taxa de reprovação e evasão em relação às demais dependências administrativas, como mostra a Tabela 10. Como 3.010.504 dos matriculados têm 18 anos ou mais (BRASIL, 2009a), provavelmente referem-se a alunos que trabalham ou procuram trabalho, em sua expressiva maioria (KUENZER, 2010).

Tabela 10 - Taxa de reprovação e evasão no ensino médio por dependência administrativa - Brasil, 2009

\begin{tabular}{l|c|c|c|c|c}
\hline \multicolumn{2}{c|}{ Brasil } & \multicolumn{4}{c}{ Dependência Administrativa } \\
\hline Taxas & Total & Federal & Estadual & Municipal & Privada \\
\hline Taxa de Reprovação & 12,6 & 12,6 & 13,5 & 10,0 & 6,2 \\
\hline Taxa de Abandono & 11,5 & 2,3 & 13,0 & 10,9 & 0,5 \\
\hline
\end{tabular}

Fonte: MEC/INEP/DEED (2009a)

Escolas urbanas sem infraestrutura adequada que oferecem ensino médio nos turnos diurno e, principalmente, noturno para alunos trabalhadores com defasagem idade/série, compondo turmas com aproximadamente 34 alunos, e com taxas elevadas de reprovação e evasão são aspectos que intensificam o trabalho do professor da última etapa da educação básica. No magistério público brasileiro, segundo Assunção e Oliveira (2009, p. 354), os mecanismos de intensificação parecem ocorrer, sobretudo se for considerada "a diversidade das condiçóes encontradas na multiplicidade de redes municipais e estaduais que comporta”.

O impacto sobre o trabalho docente, com os processos de reestruturação educacional, desencadeados a partir da década de 1990, pode ser sentido na captura da subjetividade do professor pelos reformadores, segundo Hypólito (2008), que destaca o quanto o processo de trabalho docente se encontra demasiadamente intensificado. $\mathrm{O}$ autor insiste na necessidade de se aprofundar os estudos sobre o conceito de intensificação do trabalho, para compreender os encargos colocados aos professores das escolas públicas (HYPÓLITO, 2008). O acúmulo de tarefas e funçóes pelos professores traz consequências para o corpo e, sobretudo, para a mente, podendo resultar em processos de autointensificação.

A precarização do trabalho docente se manifestou nesse estudo principalmente em três circunstâncias que se interpenetram e envolvem 
os professores da educação básica do Brasil: infraestrutura inadequada, remuneração incompatível e jornada de trabalho intensificada, entre outros fatores, os quais contribuem para que as condiçóes de trabalho docente nas escolas públicas não sejam as mais favoráveis ao bom andamento da educação e ao conforto para os que nela atuam. Tal realidade é, sem dúvida, um dos principais motivos para a baixa atratividade do magistério público no país, o que pode ser constatado pela falta de professores habilitados para lecionar nas escolas da última etapa da educação básica (BRASIL, 2007a).

As condições de trabalho, a remuneração e a jornada dos professores no Brasil podem estar levando a certo desinteresse pela docência. Tornarse professor parece não ser desejado pela maioria dos jovens que estão concluindo o ensino médio, como mostra a Tabela 11. As atividades que oferecem maior remuneração são as principais opçóes dos alunos que participaram, em 2007, do Exame Nacional do Ensino Médio (ENEM). Não considerar a urgência de melhor remuneração para os docentes, carreira que permita ganhos significativos com o tempo de docência e realização de formação continuada de forma ampla, compromete a busca de uma educação de qualidade para todos. De acordo com Sampaio e Marin (2004, p.1.223), a "relação de desvalorização e relativização total do conhecimento se articula ao desmonte da escola pública e acompanha o movimento de desvalorização das pessoas que usam a escola e fazem dela seu posto de trabalho".

Tabela 11 - Alunos do ensino médio e o desejo de tornar-se professor/2007

\begin{tabular}{c|c}
\hline Quer ser Professor & Não quer ser Professor \\
\hline $5,2 \%$ & $94,8 \%$ \\
\hline
\end{tabular}

Fonte: MEC/INEP/DIRED (2009d)

Com a ampliação da cobertura escolar e o aumento do número de docentes, observa-se a necessidade e o consequente apelo à formação em nível superior dos docentes. Tal compreensão é reforçada pela LDB 9.394/96. A partir da referida lei, intensifica-se a busca por cursos de formação inicial em nível superior. Entretanto, é significativo o número de professores da última etapa da educação básica sem habilitação específica para lecionar a disciplina em que trabalham. Mesmo considerando que 400.448 possuem licenciatura, em muitos casos seus cursos não lhes habilitam a lecionar as 
disciplinas sob sua responsabilidade. Esse cenário se agrava com os 18.195 professores não licenciados das mais diversas áreas que lecionam no ensino médio. Somam-se, ainda, os 39.703 que possuem apenas o ensino médio, e os 361 que detêm apenas o ensino fundamental (BRASIL, 2009c).

Esse contexto é ainda mais grave nas disciplinas de Física, Química, Matemática e Biologia. O ensino de Física talvez seja o mais preocupante. Dos 44.566 professores, apenas 11.238 têm licenciatura em Física. Parte da demanda é suprida, por exemplo, com 15.170 professores de Matemática e 2.636 pedagogos (BRASIL, 2009c). A falta de professores habilitados para lecionar nas escolas públicas de ensino médio intensificou-se a partir da década de 1990, com as reformas da educação e consequente ampliação do acesso à educação básica, conforme já comentado. ${ }^{1}$

O problema da "falta" de professores pode estar relacionado às demandas dentro e fora da sala de aula: cobrança constante de cumprimento de prazos, necessidade permanente de atualização, realização de inúmeras tarefas não remuneradas, como reunióes noturnas e em finais de semana, e trabalhos realizados em casa (REIS et al., 2006). Somam-se, ainda, o baixo nível de remuneração e o número excessivo de turnos, turmas, aulas e alunos sob responsabilidade do professor da última etapa da educação básica.

\section{Algumas considerações}

A partir dos anos 2000, uma ampla literatura problematiza as condições de trabalho dos professores na educação básica. A literatura visitada aponta as vicissitudes do trabalho docente realizado nas escolas públicas brasileiras. Os estudos mais recentes apontam para uma preocupante precarização da remuneração, apesar da instituição do Piso Nacional Salarial, por intermédio da Lei no $11.738 / 08$, da carreira e da jornada de trabalho do professor, o que pode comprometer uma educação de qualidade social para todos.

O modelo de regulação das políticas educativas instaurado no Brasil articulou-se em torno do papel do Estado, como propositor e avaliador de políticas públicas educacionais, e as escolas ficaram responsáveis pela implementação das ações. Tal combinação pode resultar na universalização da educação básica. O acesso ao ensino fundamental está praticamente garantido e a cobertura da educação infantil e do ensino médio está 
crescendo. A escola básica brasileira está mais pública que há vinte anos, mas há muito ainda a avançar.

Se tais políticas têm conseguido alcançar em conquistas importantes no que se refere ao acesso e permanência nas escolas, é sabido que os avanços têm representado um alto custo para os docentes. $\mathrm{O}$ contraste dos dados com a literatura permitiu perceber manifestaçóes da precarização da remuneração, da jornada e das condiçóes do trabalho na realidade do professor do ensino médio de escolas públicas.

Esses professores compóem um grupo muito singular e que foi bastante fragilizado pelas reformas. Os professores da última etapa da educação básica, em relação aos da educação infantil e ensino fundamental, segundo os dados disponíveis em fontes oficiais, são, na sua maioria, mulheres - entretanto, há mais homens nessa etapa quando comparada com as demais etapas da educação básica -, têm mais de 32 anos, são funcionários públicos de 27 Secretarias Estaduais de Educação, têm muitas aulas, turmas, alunos, turnos e empregos. Esses elementos apontam para a necessidade de maior atenção a esses profissionais.

Tal compreensão sinaliza a necessidade de estudos que possam desvelar, ainda mais, quem são esses sujeitos e suas condiçóes de trabalho. Tais argumentos ganham força na atualidade, a partir das novas açóes governamentais que incidem sobre o ensino médio. Estas abrangem a ampliação da obrigatoriedade de 4 a 17 anos, a homologação pelo ministro da Educação, em maio de 2009, das Diretrizes para os Novos Planos de Carreira e de Remuneração para o Magistério dos Estados, do Distrito Federal e dos Municípios e da decisão do Supremo Tribunal Federal (STF), em abril de 2011, que validou a Lei n.11.738/08, instituidora do Piso Nacional dos Professores de Ensino Básico das Escolas Públicas Brasileiras. Uma educação de qualidade social no Brasil só pode ser vislumbrada se as condiçôes de trabalho docente forem melhoradas. Dotar as escolas públicas e os professores do ensino médio de condiçóes apropriadas passa pela criação de um Sistema Nacional de Educação e ampliação gradativa dos atuais recursos destinados à educação, até que seja garantida a aplicação de, no mínimo, 10\% do Produto Interno Bruto (PIB) na educação básica pública, como prevê o Documento final da Conferência Nacional de Educação (CONAE), realizada em 2010 . 
A construção de uma política pública de Estado para a educação e a concretização do Sistema Nacional de Educação, contexto a ser conquistado, poderiam elevar o estatuto social e econômico dos professores brasileiros da educação básica e sustentar remuneração, carga horária e carreira docente dignas. Com professores valorizados e prestigiados, e com sólida formação teórica, pode-se vislumbrar uma educação escolar que contemple a tríade ensinar-cuidar-politizar e que oportunize a todos os brasileiros concluir a educação básica com qualidade socialmente referenciada.

\section{Nota}

1 Vide o documento "Escassez de professores no Ensino Médio: propostas estruturais e emergenciais” (BRASIL, 2007a). A comissão que elaborou o documento aponta algumas soluçóes "estruturais" e "emergenciais" visando a superar o déficit de docentes no ensino médio. O Relatório produzido pela Comissão Especial (CNE/CEB) apresenta quatorze soluçóes.

\section{REFERÊNCIAS}

ANTUNES, R.; ALVES, G. As mutaçóes do mundo do trabalho na era da mundialização do capital. Educação \& Sociedade, Campinas, v. 25, n. 87, p. 335-351, maio/ago. 2004.

ASSUNÇÃO, A. A.; OLIVEIRA, D. A. Intensificação do trabalho e saúde dos professores. Educação \& Sociedade, São Paulo, v. 30, n. 107, p. 77-99, maio/ago. 2009.

BRASIL. Emenda Constitucional no 59, de 11 de novembro de 2009. Modifica a redação do artigo 76 do Ato das Disposiçóes Constitucionais Transitórias e dá outras providências. Brasília, 2009. Disponível em: <http://www.planalto.gov.br/ccivil_03/constituicao/emendas/emc/ emc59.htm>. Acesso em: 2 jan. 2011.

BRASIL. Ministério da Educação. Instituto Nacional de Estudos e Pesquisas Educacionais Anísio Teixeira (INEP). Resumo Técnico: Censo Escolar. Brasília: MEC/Inep/DEED, 2010. 
BRASIL. Resolução no 2, de 28 de maio de 2009. Fixa as Diretrizes Nacionais para os Planos de Carreira e Remuneração dos Profissionais do Magistério da Educação Básica Pública. Brasília, 2009.

BRASIL. Censo escolar da educação básica. Brasília: MEC/INEP/ Diretoria de Estatísticas Educacionais (DEED), 2009a.

BRASIL. Sinopse do Professor da Educação Básica. Brasília: MEC/INEP/ DEED, 2009b.

BRASIL. Estudo exploratório sobre o professor brasileiro: com base nos resultados do Censo Escolar da Educação Básica 2007. Brasília: MEC/ INEP/DEED, 2009c.

BRASIL. Quem quer ser professor no Brasil? O que o Enem nos diz. Brasília: Boletim de Estudos Educacionais do Inep - MEC/Inep/Diretoria de Estudos Educacionais (DIRED), 2009d.

BRASIL. Lei no 11.738, de 16 de julho de 2008. Regulamenta a alínea "e" do inciso III do caput do art. 60 do Ato das Disposiçóes Constitucionais Transitórias, para instituir o piso salarial profissional nacional para os profissionais do magistério público da educação básica. Diário Oficial da União, Brasília, 2008. Disponível em: <http://www. planalto.gov.br/ccivil_03/_ato2007-2010/2008/lei/111738.htm>. Acesso em: 10 fev. 2011.

BRASIL. Lei n. 11.494, de 20 de junho de 2007. Regulamenta o Fundo de Manutenção e Desenvolvimento da Educação Básica e de Valorização dos Profissionais da Educação (FUNDEB). Brasília, 2007. Disponível em: <http:/www.planalto.gov.br/ccivil_03/_Ato2007-2010/2007/Lei/ L11494.htm>. Acesso em: 02 jan. 2011.

BRASIL. Escassez de professores no ensino médio: propostas estruturais e emergenciais. Brasília: CNE/CEB, 2007a.

BRASIL. Decreto n. 5154, de 23 de Julho de 2004. Regulamenta o $\$ 2^{\circ}$ do art. 36 e os arts. 39 a 41 da Lei no 9.394, de 20 de dezembro de 1996, que estabelece as diretrizes e bases da educação nacional, e dá outras providências. Brasília, 2004. Disponível em: <http://www.planalto.gov. br/ccivil_03/_ato2004-2006/2004/decreto/D5154.htm>. Acesso em: 2 jan. 2011. 
BRASIL. Conselho Nacional de Educação. Diretrizes Curriculares Nacionais para o Ensino Médio. Parecer CEB no 15/98, aprovado em 1/6/98 (Processo no 23001.000309/97-46). Brasília, 1998.

BRASIL. Emenda Constitucional n. 14, de 12 de setembro de 1996. Modifica os artigos 34, 208, 211 e 212 da Constituição Federal. Brasília, 1996. Disponível em: <http://www.planalto.gov.br/ccivil_03/ constituicao/emendas/emc/emc14.htm>. Acesso em: 2 jan. 2011.

BRASIL. Lei no 9.424, de 24 de dezembro de 1996. Dispóe sobre o Fundo de Manutenção do Ensino Fundamental e de Valorização do Magistério (FUNDEF). Brasília, 1996. Disponível em: <http://www. planalto.gov.br/ccivil_03/leis/L9424.htm>. Acesso em: 2 jan. 2011.

BRASIL. Lei no 9.394, de 20 de dezembro de 1996. Estabelece as diretrizes e bases da educação nacional. Diário Oficial da União, Brasília, 1996. Disponível em: <http://www.planalto.gov.br/ccivil_03/leis/L9394. htm>. Acesso em: 10 fev. 2011.

BRASIL. Constituição (1988). Constituição da República Federativa do Brasil. Brasília, DF: Senado, 1988.

CEARÁ. Análise Comparativa Salarial: Professores das Redes Estaduais do Brasil. Ceará: Sindicato dos Professores e Servidores no Estado do Ceará, 2010. Disponível em: <http://www.apeoc.org.br/extra/pesquisa. salarial.apeoc.pdf>. Acesso em: 2 jan. 2011.

CONFERÊNCIA NACIONAL DE EDUCAÇÃO (CONAE), 2010, Brasília, DF. Construindo o Sistema Nacional Articulado de Educação: o Plano Nacional de Educação, diretrizes e estratégias. Brasília, DF: MEC, 2010.

DECLARAÇÃO mundial sobre educação para todos e plano de ação para satisfazer as necessidades básicas de aprendizagem. Nova York: UNICEF, 1990.

DOURADO, L. F.; OLIVEIRA, J. F. Verbos intransitivos para uma política pública: formar, valorizar e profissionalizar. Revista Retratos da Escola, Brasília, v. 2. n. 2-3, p. 7-13, jan./dez. 2008.

FERREIRA JUNIOR, A.; BITTAR, M. A ditadura militar e a proletarização dos professores. Educação \& Sociedade, Campinas, v. 27, n. 97, p. 1159-1179, set./dez. 2006. 
GARCIA, M. M. A.; ANADON, S. B. Reforma educacional, intensificação e autointensificação do trabalho docente. Educação \& Sociedade, Campinas, v. 30, n. 106, p. 63-85, jan./abr. 2009.

HYPOLITO, A. M. Intensificação e autointensificação do trabalho docente no contexto de reestruturação educativa. In: SEMINÁRIO DA REDESTRADO: NUEVAS REGULACIONES EN AMERICA LATINA, 7., 2008, Buenos Aires. Anais... Buenos Aires, 2008.

KUENZER, A. Z. O ensino médio no Plano Nacional de Educação 2011-2020: superando a década perdida? Educação \& Sociedade, Campinas, v. 31, n. 112, p.851-873, jul./set. 2010.

LEHER, R.; LOPES, A. Trabalho docente, carreira e autonomia universitária e mercantilização da educação. In: SEMINÁRIO DA REDESTRADO: NUEVAS REGULACIONES EN AMERICA LATINA, 7., 2008, Buenos Aires. Anais... Buenos Aires, 2008.

MANCEBO, D. Agenda de pesquisa e opçóes teórico-metodológicas nas investigações sobre o trabalho docente. Educação \& Sociedade, v. 28, n. 99, p. 466-482, maio/ago. 2007.

ORGANIZAÇÃO para a Cooperação e Desenvolvimento Econômico (OCDE). Pesquisa Internacional sobre Ensino e Aprendizagem - TALIS, 2007-2008.

OECD. Education at a glance: 2002 OECD Indicators. OECD Publications, 2002.

OLIVEIRA, D. A. A reestruturação do trabalho docente: precarização e flexibilização. Educação \& Sociedade, Campinas, v. 25, n. 89, p. 1.1271.144, set./dez. 2004.

OLIVEIRA, D. A. O Ensino Médio diante da obrigatoriedade ampliada: que liçóes podemos tirar de experiências observadas? Revista Brasileira de Estudos Pedagógicos, Brasília, v. 91, n. 228, p. 269-290, maio/ago. 2010.

OLIVEIRA, D. A. O trabalho docente na América Latina: identidade e profissionalização. Revista Retratos da Escola, Brasília, v. 2, n. 2-3, p. 2939, jan./dez. 2008. 
OLIVEIRA, D. A. Regulação educativa na América Latina: repercussóes sobre a identidade dos trabalhadores docentes. Educação em Revista, Belo Horizonte, v. 44, p. 209-227, 2006.

PESQUISA NACIONAL POR AMOSTRA DE DOMICÍLIOS (PNAD). Brasil. Rio de Janeiro: IBGE, 2006.

REIS, E. J. F. B. et al. Docência e exaustão emocional. Educação \& Sociedade, Campinas, v. 27, n. 24, p. 229-253, jan./abr. 2006.

SAMPAIO, M.; MARIN, A. Precarização do trabalho docente e seus efeitos sobre as práticas curriculares. Educação \& Sociedade, Campinas, v. 25, n. 89, p. 1.203-1.225, set./dez. 2004. 


\section{Secondary school teaching in Brazil}

\section{Abstract}

This article aims to discuss who the secondary school teachers in Brazil are and under which conditions they do their job, based upon statistics available from official sources and literature review. According to these data, compared to early childhood and elementary education, secondary school teachers have a greater number of classes, students, work shifts and job posts. The article starts by characterizing the context of the educational reforms that Brazil has experienced in the last two decades. As a result, there was a significant quantitative expansion of enrollment in basic education, which has brought important consequences for the secondary school teachers. Teachers of the final stage of basic education do not have adequate working conditions and compensation for their high responsibilities. Poor working conditions and remuneration of teachers may result in a low attractiveness of the teaching career in Brazil.

Keywords: Teaching work conditions. Secondary school. Teacher.

\section{Trabajo docente en la enseñanza média en Brasil}

\section{Resumen}

Este artículo tiene como objetivo discutir quién son los sujetos docentes de la enseñanza media de Brasil y sus condiciones de trabajo, a partir de los datos estadísticos disponibles en fuentes oficiales y en la literatura. De acuerdo con ellos, los profesores de la enseñanza media en Brasil, cuando comparados a los profesores de la educación infantil de la enseñanza fundamental, tienen más clases, turmas, alumnos y empleos. El texto parte de la caracterización del contexto de reformas educacionales que el país vivió en las dos últimas décadas, resultando en expansión cuantitativa de inscripción en la educación básica, lo que aporta consecuencias importantes para los docentes de la enseñanza media. Estos docentes de la última etapa de la educación básica no cuentan con condiciones de trabajo y de remuneración compatibles con las innúmeras demandas que llegan a las escuelas. Sus condiciones de trabajo, carrera y remuneración pueden tener, como resultado, un bajo interés por la carrera de magisterio en Brasil.

Palabras-clave: Condiciones del trabajo docente. Enseñanza media. Docente.

\section{Gilvan Luiz Machado Costa}

E-mail: gilvan.costa@unisul.br

\section{Dalila Andrade Oliveira}

E-mail: dalila@fae.ufmg.br

Recebido em: 18/12/2010

Versáo final recebida em: 2/11/2011

Aprovado em: 10/11/2011 